\title{
PHARMACOKINETIC STUDIES IN ANIMALS OF A NEW PARENTERAL PENEM CP-65,207 AND ITS ORAL PRODRUG ESTER ${ }^{\dagger}$
}

\author{
Thomas Gootz, Dennis Girard, William Schelkley, Thomas Tensfeldt, \\ George Foulds, Michael Kellogg, John Stam, Benedict Campbell ${ }^{\dagger \dagger}$, \\ John Jasys, Paul Kelbaugh, Robert Volkmann and Ernest Hamanaka \\ Pfizer Central Research; \\ Groton, CT, U.S.A. \\ ${ }^{\dagger \dagger}$ Department of Biochemistry, University of Missouri, \\ Columbia, MO, U.S.A.
}

(Received for publication August 2I, 1989)

\begin{abstract}
The pharmacokinetics of penem CP-65,207 diastereomeric mixture were studied following parenteral administration in mice, rats, beagle dogs and cynomolgus monkeys. As is characteristic for most penems, the serum elimination $\mathrm{T}_{1 / 2}$ of CP-65,207 in rodents was only 13 minutes for mice and 18 minutes for rats. A linear relationship was observed between dose and Cmax following subcutaneous injection of drug in mice. The $T_{1 / 2}$ in the beagle dog and monkey following intravenous injection was approximately 23 minutes. CP-65,207 demonstrated binding to human serum proteins of only $10 \%$. In vitro studies using purified porcine renal dehydropeptidase-I (RDHP) indicated that the pure $S$-isomer of CP-65,207 was 7 -fold more stable to inactivation than imipenem. Urinary recovery of CP-65,207 in the dog was $42 \%$ compared to $1 \%$ for imipenem without RDHP inhibitor. Unlike results obtained with imipenem, coadministration of probenecid with CP-65,207 in the dog doubled the elimination $T_{1 / 2}$ and AUC of the penem demonstrating its relative stability in vivo in the absence of a RDHP inhibitor. The pivaloyloxymethyl esters of each pure isomer of CP-65,207 showed significantly different degrees of oral absorption in rats.
\end{abstract}

Carbapenem and penem antimicrobials are $\beta$-lactams that have demonstrated broad spectrum and high potency in vitro ${ }^{2 \sim 9)}$. Aside from their antibacterial potency, some penems show oral absorption in vivo, and all are susceptible to hydrolysis by renal dehydropeptidase-I (RDHP) found in the brush border of the kidney in animals and $\operatorname{man}^{10,11)}$. Imipenem is the first carbapenem used clinically and it is coadministered with a RDHP inhibitor to block its high degree of renal metabolism ${ }^{12 \sim 14)}$. Several reports have studied the pharmacokinetics of experimental penem and carbapenem antimicrobials in an attempt to predict the performance of these compounds in humans ${ }^{12,15,16)}$. HAJDU et al. ${ }^{17}$ determined that in rodents, extensive extrarenal metabolism of some analogs occurred by dehydropeptidases and that susceptibility to these enzymes significantly affected pharmacokinetic parameters in this model. In another report ${ }^{15}$, interspecies pharmacokinetic scaling in animals of penem SCH-34343 was useful in predicting the plasma elimination $T_{1 / 2}$ of this compound in man. Studies in several animal species were also helpful in elucidating the renal metabolism of imipenem ${ }^{12)}$.

CP-65,207 (Fig. 1) is a new broad spectrum penem antimicrobial for parenteral administration that is composed of an equal mixture by weight of $S$ and $R$-stereoisomers ${ }^{18}$. The current study evaluates the pharmacokinetics of this compound in mice, rats, dogs, and cynomolgus monkeys. The oral absorption of the pivaloyloxymethyl (POM) ester of CP-65,207 is also studied in rats and monkeys. Finally, the effect of RDHP on the metabolism of CP-65,207 is compared relative to that of imipenem.

\footnotetext{
${ }^{\dagger}$ Presented in part at the 28 th Intersci. Conf. on Antimicrob. Agents Chemother. ${ }^{1)}$.
} 
Fig. 1. Stereoisomers of CP-65,207 and RDHP inhibitor.

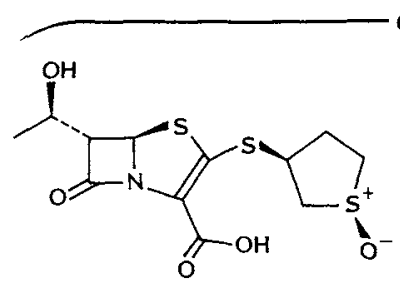

CP-70,429

$(S$-isomer)

CP-65,207

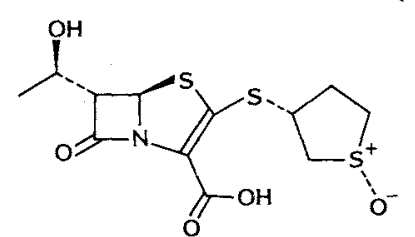

CP-81,054

$(R$-isomer)



Renal dehydropeptidase inhibitor

\section{Materials and Methods}

\section{Test Compounds}

CP-65,207 was synthesized at Pfizer Central Research as a diastereomeric mixture composed of equal amounts of $S$ (CP-70,429) and $R$ (CP-81,054)-stereoisomers (Fig. 1). SCH-29482 was synthesized in-house. SCH-34343 was obtained from the Schering Corp., Bloomfield, New Jersey. A renal dehydropeptidase inhibitor (Fig. 1) that is different from cilastatin was synthesized in-house. Imipenem (without cilastatin) in a sodium salt form was a gift from Merck Sharp and Dohme, Rahway, NJ. Benzylpenicillin and probenecid powders were purchased from Sigma Chemical Co., St. Louis, MO.

\section{Experimental Design}

Male and female outbred CDI mice (average body weight $25 \mathrm{~g}$ ) and male outbred CD rats (70 to $90 \mathrm{~g}$ ) were purchased from Charles River Breeding Laboratories, Inc., Kingston, RI. Purebred male beagle dogs $(10 \sim 12 \mathrm{~kg})$ and female cynomolgus monkeys $(2.5$ to $4.0 \mathrm{~kg})$ were obtained from colonies maintained at Pfizer Inc.

Single subcutaneous doses of CP-65,207 dissolved in sterile saline ( $\mathrm{pH} 7.0$ ) were administered to mice and rats (at doses up to $12.5 \mathrm{mg} / \mathrm{kg}$ ) while dogs and monkeys were dosed intravenously with drug $(10 \mathrm{mg} / \mathrm{kg})$. All animals were given food and water ad libidum throughout the study period. For studies measuring the oral absorption of the POM ester form of each isomer of CP-65,207, rats fasted for 24 hours were given drug doses of $50 \mathrm{mg} / \mathrm{kg}$, as an oral suspension in a standard diluent ${ }^{19)}$ containing methocel $15(0.5 \mathrm{~g})$, polysorbate $80(1.0 \mathrm{~g})$, carboxymethylcellulose (CMC $70 \mathrm{low})(10.0 \mathrm{~g})$, sodium chloride $(9.0 \mathrm{~g})$, and water $(984 \mathrm{ml})$. Oral dose volumes were $0.5 \mathrm{ml}$ for rats. The oral absorption of each penem isomer was determined following crossover studies with parenterally administered penem.

Mouse and rat peripheral blood samples were obtained by retroorbital bleeding into heparinized capillary pipettes. Serial blood samples were obtained between 15 and 120 minutes after dosing in mice and rats and up to 4 hours for dogs and monkeys.

In order to study the intestinal absorption of intact prodrug of CP-65,207, two cynomolgus monkeys were anesthetized initially with ketamine followed by a mixture of fluothane/nitrous oxide, and a $5.1-\mathrm{cm}$ incision was made along the ventral midline. A suspension of CP-65,207 POM ester equivalent to $50 \mathrm{mg} / \mathrm{kg}$ CP-65,207 was prepared in distilled water and injected directly into the duodenum. Samples of whole blood were taken from the portal vein and femoral triangles at timed intervals after dosing. Samples were immediately processed and analyzed by HPLC for content of unhydrolyzed POM ester and both isomers of CP-65,207.

\section{Antibiotic Detection Assays}

Concentrations of CP-65,207 were determined in plasma, serum, or urine on the same day of collection by an agar diffusion method with Bacillus subtilis ATCC 6633 that was equally susceptible to both isomers, as the indicator organism. Standard curves of drug were prepared over a relevant concentration range in each biological fluid analyzed. A UV-HPLC assay was developed to measure both diastereomers of CP-65,207 in blood and urine. Samples were assayed using $1 \mathrm{ml}$ solid phase extraction SAX Bond Elute Cartridges (Analytical International, Inc., Harbor city, CA). Subsequent analysis was done with a Waters 
Nova Pak $5 \mu \mathrm{M} \mathrm{C18}$ column (Waters Corp., Milford, MA), clearly separating the isomers with detection at $313 \mathrm{~nm}$.

\section{Data Analysis}

Plasma and serum pharmacokinetic parameters were calculated for individual animals over the entire sampling period and subsequent mean values were determined where appropriate, by averaging the values for all of the animals in a dose group. Pharmacokinetic data are expressed in terms of means and standard errors.

Pharmacokinetic parameters were defined as follows. Tmax corresponds to the time that peak drug levels Cmax were observed. Half-life was determined from the elimination rate constant as calculated by linear regression analysis ${ }^{20}$. Area under the curve $\left(\mathrm{AUC}_{0-\infty}\right)$ corresponds to the AUC from zero time to infinity, as calculated by the trapezoidal rule through the last time point and the terminal areas as determined from the ratio of the last concentration to the terminal rate constant.

\section{Urinary Recovery}

The effect of coadministration of a RDHP inhibitor (Fig. 1) on the renal elimination of CP-65,207 in the dog was compared to that of imipenem and benzylpenicillin in the presence and absence of probenecid. An adult male beagle dog was used to test these combinations for each antibiotic in a multiple crossover study. CP-65,207 or imipenem was given as a single intravenous dose of $10 \mathrm{mg} / \mathrm{kg}$. The RDHP inhibitor was administered subcutaneously at $100 \mathrm{mg} / \mathrm{kg}, 30$ minutes before, along with, and 60 minutes after injection of antibiotic ${ }^{12)}$. Probenecid was administered subcutaneously at $20 \mathrm{mg} / \mathrm{kg} 30$ minutes before and 30,60 , 90 , and 120 minutes after each antibiotic. Blood and urine were collected by standard methods and assayed for bioactive antibiotic using B. subtilis ATCC 6633.

\section{Stability Studies with Purified Renal Dehydropeptidases}

The in vitro stability of both isomers of CP-65,207 to purified porcine and human RDHP was determined ${ }^{21}$. The catalytic activity of each enzyme was standardized against $0.52 \mathrm{~mm}$ glycyldehydrophenylalanine as substrate in $2 \mathrm{~mm}$ Tris- $\mathrm{HCl}$ buffer $\left(\mathrm{pH} \mathrm{7.4)}\right.$ ) at $37^{\circ} \mathrm{C}$ using a spectrophotometric method ${ }^{21)}$. Each test compound was made to $0.15 \mathrm{~mm}$ in MOPS buffer ( $\mathrm{pH} 7.1$ ) and the hydrolysis of the $\beta$-lactam ring was monitored at $300 \mathrm{~nm}$ at an incubation temperature of $37^{\circ} \mathrm{C}$.

\section{Binding to Human Serum Proteins}

The binding and stability of $\mathrm{CP}-65,207$ diastereomeric mixture to pooled human serum was determined by a spectrophotometric assay as described previously ${ }^{22}$. The amount of drug bound to serum proteins was determined by adjusting whole human serum $(\mathrm{pH} 7.4)$ to a drug concentration of $20 \mu \mathrm{g} / \mathrm{ml}$ at $25^{\circ} \mathrm{C}$, followed by centrifugation through a Centrifree (Amicon Corp., Lexington, MA) filter that retained $>99.9 \%$ of serum protein. The degree of penem protein binding was determined spectrophotometrically by measuring unbound drug in the ultrafiltrate at $322 \mathrm{~nm}$.

\section{Results}

\section{Plasma Kinetics after Parenteral Administration}

The pharmacokinetics of CP-65,207 were studied following parenteral doses to mice, rats, dogs, and cynomolgus monkeys. The data in Figs. 2 and 3, and Table 1, indicate that like most other penems and carbapenems, the elimination $\mathrm{T}_{1 / 2}$ of $\mathrm{CP}-65,207$ is short in rodents (13 minutes for mice and 18 minutes for rats). A linear relationship was observed between dose and $\mathrm{Cmax}$ in mice given subcutaneous doses of CP-65,207 from 3.12 to $12.5 \mathrm{mg} / \mathrm{kg}$ (Fig. 2). At intravenous doses of $10 \mathrm{mg} / \mathrm{kg}, \mathrm{CP}-65,207$ had higher serum levels in the dog and monkey, with at least 7-fold increases in Cmax and AUC compared to those obtained in the rat (Figs. 4 and 5) and Table 1. When administered intravenously as a $1: 1$ mixture of isomers in the monkey at $10 \mathrm{mg} / \mathrm{kg}$, about equal amounts of each isomer of CP-65,207 were detected in plasma by the HPLC method (data not shown). This similarity in the plasma pharmacokinetics of both 
Fig. 2. Plasma elimination curves of CP-65,207 dosed subcutaneously in mice.

- $3.12 \mathrm{mg} / \mathrm{kg}, \boldsymbol{\Delta} 6.25 \mathrm{mg} / \mathrm{kg}, 12.5 \mathrm{mg} / \mathrm{kg}$.

$n=5$ per dose group. Active drug measured by bioassay.

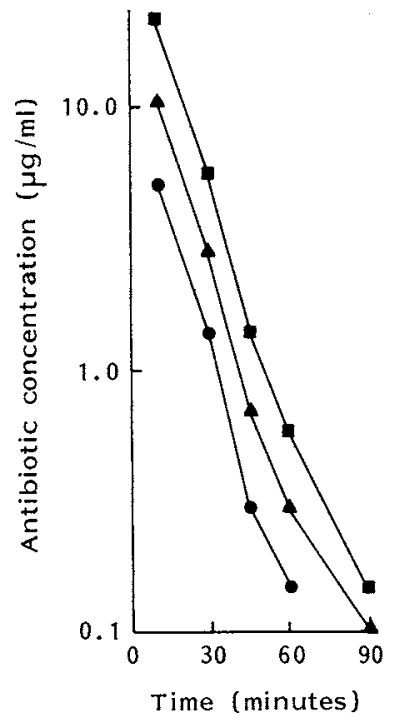

Fig. 4. Serum elimination curve of CP-65,207 dosed $10 \mathrm{mg} / \mathrm{kg}$ súbcutaneously in dogs $( \pm 1 \mathrm{SEM}) n=6$.

Active drug measured by bioassay.

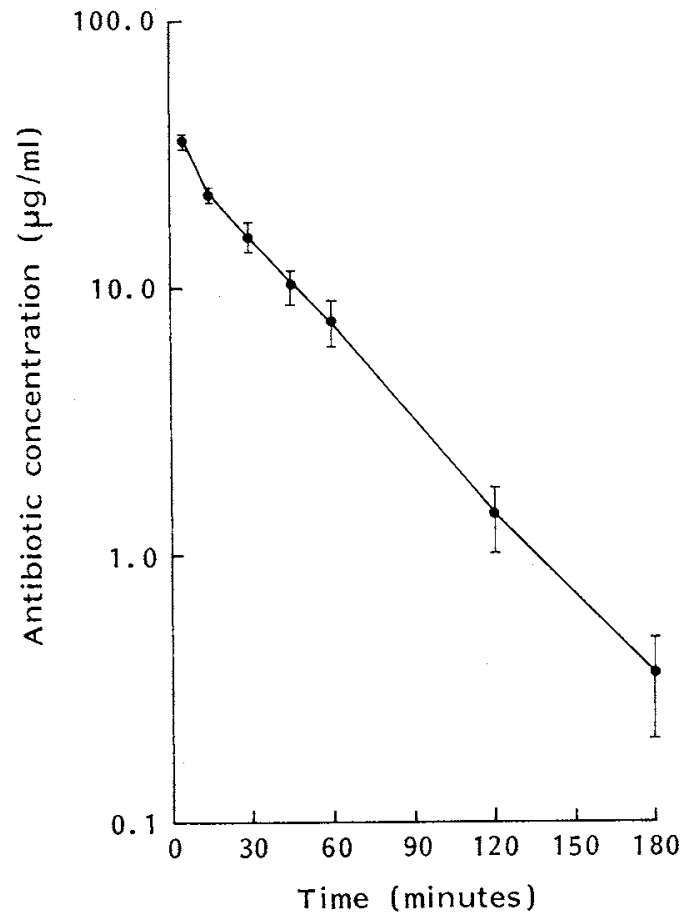

Fig. 3. Plasma elimination curve of CP-65,207 dosed $10 \mathrm{mg} / \mathrm{kg}$ subcutaneously in rats $( \pm 1 \mathrm{SEM}) n=10$.

Active drug measured by bioassay.

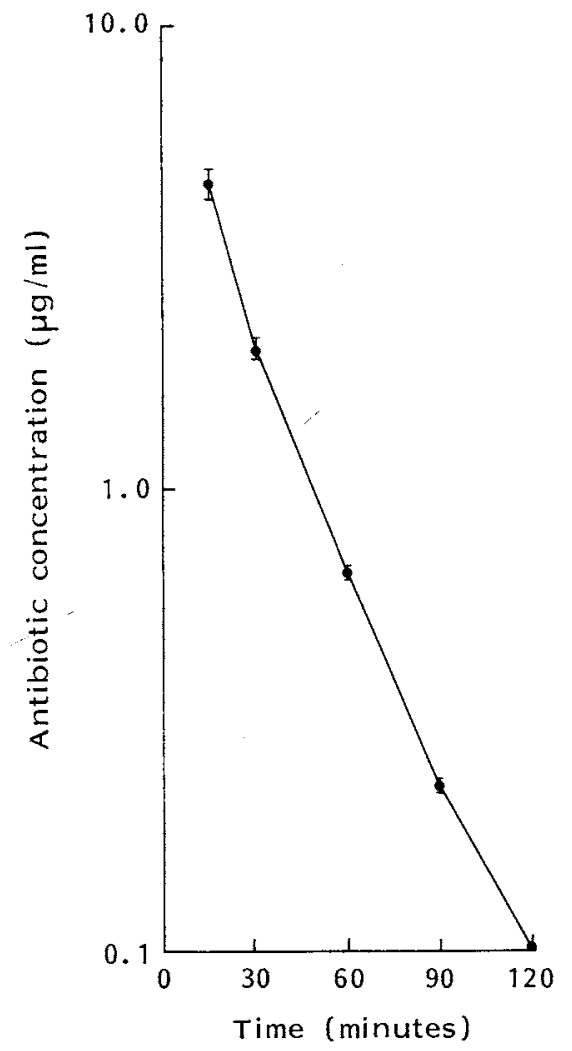

Fig. 5. Serum elimination of individual isomers (CP-70,429 and CP-81,054) of CP-65,207 each dosed $10 \mathrm{mg} / \mathrm{kg}$ intravenously in cynomolgus monkeys $(n=2)$ in a crossover design study.

$\square$ CP-70,429 ( $S$-isomer), O CP-81,054 ( $R$-isomer). Drug assayed by HPLC.

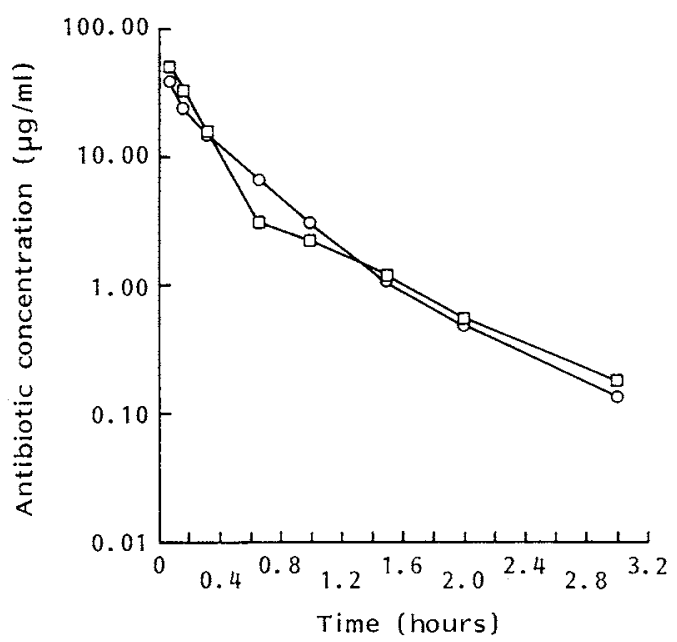


Table 1. Pharmacokinetic parameters of CP-65,207 in various animals.

\begin{tabular}{|c|c|c|c|c|}
\hline $\begin{array}{c}\text { Species } \\
\text { (number tested) }\end{array}$ & $\begin{array}{c}\text { Dose } \\
(\mathrm{mg} / \mathrm{kg})\end{array}$ & $\begin{array}{l}\mathrm{Cmax}^{\mathrm{a}} \\
(\mu \mathrm{g} / \mathrm{ml})\end{array}$ & $\begin{array}{c}\mathrm{T}_{1 / 2} \beta \\
\text { (minutes) }\end{array}$ & $\begin{array}{c}\mathrm{AUC}_{0-\infty} \\
(\mu \mathrm{g} \cdot \text { hours } / \mathrm{ml})\end{array}$ \\
\hline Mouse $(n=5) \mathrm{sc}^{\mathrm{b}}$ & 12.5 & $21.1(0.2)$ & $13.2(0.6)$ & $7.4(0.4)$ \\
\hline Rat $(n=10) \mathrm{sc}$ & 10 & $4.6(0.3)$ & $17.9(0.9)$ & $2.4(0.1)$ \\
\hline Beagle $(n=6) \mathrm{iv}^{c}$ & 10 & $35.3(5.9)$ & $23.4(3.0)$ & $21.7(2.4)$ \\
\hline \multicolumn{5}{|c|}{ Cynomolgus monkey $(n=2)$ iv } \\
\hline$S$-Isomer CP-70,429 & 10 & 51.4 & 22.8 & 15.5 \\
\hline$R$-Isomer CP-81,054 & 10 & 39.5 & 24.6 & 14.6 \\
\hline
\end{tabular}

Fig. 6. Plot of interspecies correlation between elimination $T_{1 / 2}$ and body weight for CP-65,207 dosed parenterally.

Data for man obtained with $1 \mathrm{~g}$ intravenous dose $\mathrm{e}^{23)}$.

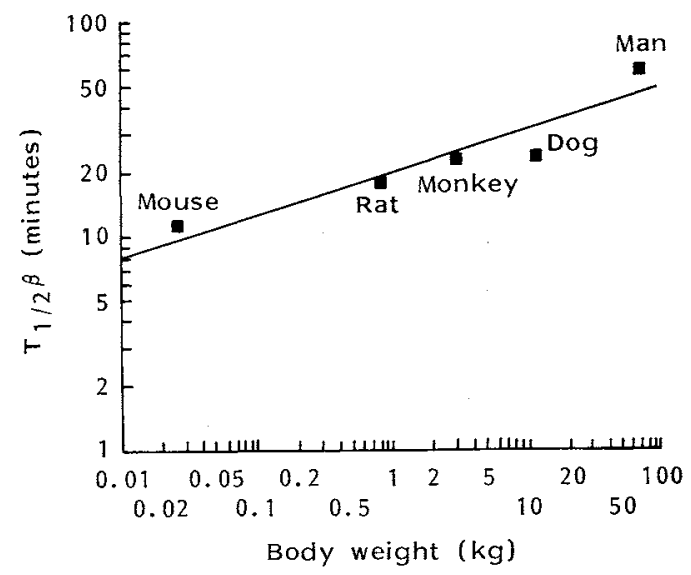

isomers was confirmed in monkeys dosed individually with the separate penem isomers CP-70,429 and CP-81,054 (Fig. 5 and Table 1).

When a plot of the serum elimination $\mathrm{T}_{1 / 2} \beta$ and species body weight is made, the relationship shown
Table 2. Interaction of penems with human serum.

\begin{tabular}{lcc}
\hline Compound & $\begin{array}{c}\text { Bound } \\
(\%)\end{array}$ & $\begin{array}{c}\text { Relative } \\
\text { hydrolysis }\end{array}$ \\
\hline CP-65,207 & 10 & 0.61 \\
SCH-29482 & 94 & 1.0 \\
SCH-34343 & 63 & 0.56 \\
\hline a & As determined by ultrafiltration of whole serum. \\
b & Relative molar velocity of hydrolysis in $50 \%$ serum \\
& at $37^{\circ} \mathrm{C}$. SCH-29482 assigned a value of 1.0.
\end{tabular}

Table 3. Stability of penem isomers and imipenem to purified renal dehydropeptidases.

\begin{tabular}{cccccc}
\hline \multirow{2}{*}{ Compound } & \multicolumn{2}{c}{ Human RDHP } & & \multicolumn{2}{c}{ Porcine RDHP } \\
\cline { 2 - 3 } \cline { 5 - 6 } & $\begin{array}{c}\text { Hydrolysis } \\
(\%)\end{array}$ & $\begin{array}{c}\text { Initial } \\
\text { velocity }\end{array}$ & $\begin{array}{c}\text { Hydrolysis } \\
(\%)\end{array}$ & $\begin{array}{c}\text { Initial } \\
\text { velocity }\end{array}$ \\
\hline Imipenem & $2.96^{\mathrm{a}}$ & $0.0086^{\mathrm{b}}$ & & 23.29 & 0.072 \\
$\mathrm{CP}-70,429$ & 1.43 & 0.0047 & & 3.09 & 0.008 \\
$\begin{array}{c}(S \text {-isomer }) \\
\text { CP-81,054 } \\
(R \text {-isomer })\end{array}$ & 2.25 & 0.0078 & & 4.01 & 0.011 \\
\hline
\end{tabular}

a Percent hydrolysis of a $0.15-\mathrm{mm}$ solution of substrate in 20 minutes using a spectrophotometric assay.

b Initial velocity of the reaction in $\mu \mathrm{mol} / \mathrm{minute} / \mathrm{U}$ of enzyme.

in Fig. 6 is found. $T_{1 / 2}$ correlated well with body weight among the species tested, suggesting that this interspecies correlation might have predictive value for determining the $T_{1 / 2}$ of $C P-65,207$ in humans.

In vitro assays were performed in order to measure the interaction of CP-65,207 with human serum. As shown in Table 2, the protein binding of CP-65,207 was low, in good agreement with the large volume of distribution observed for the compound in both monkeys and humans ${ }^{23}$. CP-65,207 was also stable in the presence of 50\% human serum when compared to penems SCH-29482 and SCH-34343 (Table 2).

\section{Stability to Renal Dehydropeptidases}

In order to compare the relative stability of CP-65,207 to hydrolysis by RDHP, each separate isomer of the penem was tested against purified porcine and human enzymes in a spectrophotometric assay. The results indicate that the $S$-isomer, CP-70,429 is 7.5 -fold more stable than imipenem to hydrolysis by the porcine enzyme and twice as stable against the purified human enzyme (Table 3 ). The $S$-isomer of CP-65,207 
Fig. 7. Effect of probenecid on the elimination of imipenem, benzylpenicillin, and CP-65,207 in the dog.

(A) Imipenem, (B) benzylpenicillin, (C) CP-65,207. - Imipenem, O imipenem + probenecid, benzylpenicillin, $\triangle$ benzylpenicillin + probenecid, a CP-65,207, $\square$ CP-65,207+ probenecid.

(A)

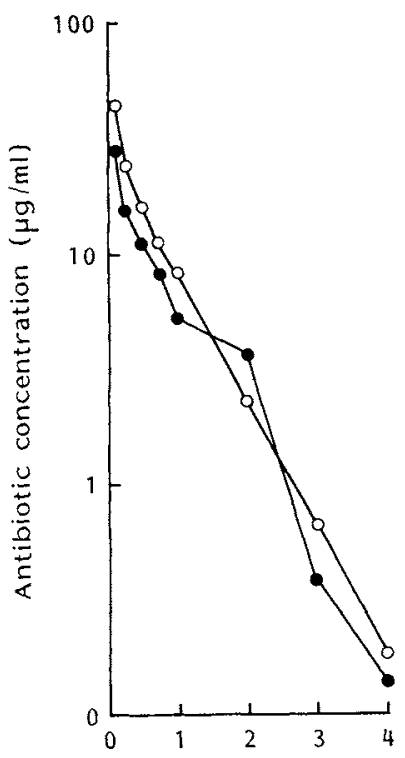

(B)

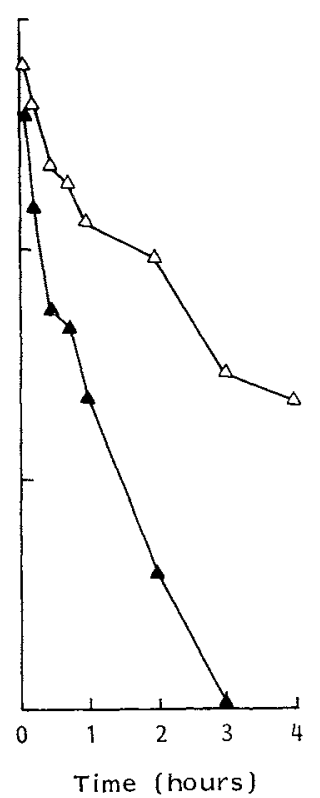

(c)

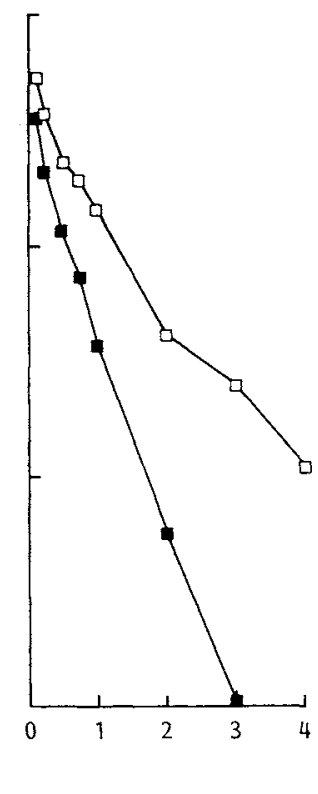

Antibiotics given as single $10 \mathrm{mg} / \mathrm{kg}$ dose intravenously. Probenecid dosed $20 \mathrm{mg} / \mathrm{kg} 30$ minutes before and $30,60,90$, and 120 minutes after each antibiotic. Active drug measured by bioassay.

was 1.6 times more stable against the human enzyme than the $R$-isomer in these studies.

Effect of a RDHP Inhibitor on the Metabolism of CP-65,207

Coadministration of the RDHP inhibitor cilastatin with imipenem has been shown to significantly decrease the extensive renal metabolism of the carbapenem in both animals and man ${ }^{12,13)}$. Since both isomers of CP-65,207 demonstrated some degree of increased stability to cell-free RDHP compared to imipenem, further studies were performed in the dog to determine whether coadministration of a RDHP inhibitor would decrease the renal metabolism of the penem. These tests also evaluated the effects of coadministering probenecid with CP-65,207 compared with the effect of this compound on the elimination of imipenem and benzylpenicillin. Fig. 7(A) illustrates the serum elimination curve in the dog following a $10-\mathrm{mg} / \mathrm{kg}$ intravenous dose of imipenem (without RDHP inhibitor) in the presence and absence of probenecid. In agreement with results of other investigators ${ }^{12)}$, probenecid had no effect on the elimination of imipenem in the absence of RDHP inhibitor. Fig. 7(B) shows a similar study in the dog with benzylpenicillin, a compound that undergoes significant tubular secretion but is not susceptible to hydrolysis by RDHP. In this experiment, probenecid significantly extends the amount of circulating benzylpenicillin as expected. In a similar manner, probenecid alone significantly prolongs the renal elimination of CP-65,207 (Fig. 7(C)). Since this effect was achieved without administration of a RDHP inhibitor, it is likely that CP-65,207 is not as susceptible as imipenem to hydrolysis in the proximal tubule. The data in Table 4 support this conclusion. The percent of intravenous dose of CP-65,207 in the absence of a RDHP inhibitor recovered in dog urine in 24 hours was $41 \%$. In contrast, only $1 \%$ of the same dose of imipenem was 
Table 4. Renal elimination studies in the $\operatorname{dog}(n=1)$.

\begin{tabular}{|c|c|c|c|c|}
\hline & Antibiotic alone $\mathrm{a}^{\mathrm{a}}$ & $\begin{array}{l}\text { Antibiotic }+ \\
\text { probenecid }^{b}\end{array}$ & $\begin{array}{c}\text { Antibiotic }+ \\
\text { dipeptidase } \\
\text { inhibitor }^{c}\end{array}$ & $\begin{array}{l}\text { Antibiotic } \\
\text { dipeptidase } \\
\text { inhibitor } \\
\text { probenecid }\end{array}$ \\
\hline \multicolumn{5}{|l|}{ Imipenem } \\
\hline AUC & 17 & 25 & 22 & 34 \\
\hline $\mathrm{T}_{1 / 2} \beta$ (minutes) & 30 & 30 & 42 & 42 \\
\hline Urinary recovery $(\%)$ & 1 & 3 & 14 & 25 \\
\hline \multicolumn{5}{|l|}{$\mathrm{CP}-65,207$} \\
\hline $\mathrm{AUC}$ & 17 & 44 & 26 & 34 \\
\hline $\mathrm{T}_{1 / 2} \beta$ (minutes) & 21 & 42 & 29 & 46 \\
\hline Urinary recovery (\%) & 41 & 38 & 38 & 46 \\
\hline \multicolumn{5}{|l|}{ Benzylpenicillin } \\
\hline AUC & 12 & 50 & - & - \\
\hline $\mathrm{T}_{1 / 2} \beta$ (minutes) & 23 & 53 & - & - \\
\hline Urinary recovery $(\%)$ & 32 & 46 & - & - \\
\hline \multicolumn{5}{|c|}{ a CP-65,207, imipenem, and benzylpenicillin single dose iv of $10 \mathrm{mg} / \mathrm{kg}$. } \\
\hline \multicolumn{5}{|c|}{ b Probenecid dosed sc $20 \mathrm{mg} / \mathrm{kg}-30,30,60,90$, and 120 minutes around antibiotic dose. } \\
\hline \multicolumn{5}{|c|}{ c Renal dipeptidase inhibitor dosed sc $100 \mathrm{mg} / \mathrm{kg}-30,30$, and 60 minutes around antibiotic dose. } \\
\hline \multicolumn{5}{|c|}{ a Percent urinary recovery of bioactive antibiotic over 24 hours. } \\
\hline
\end{tabular}

recovered. The 24-hour recovery of imipenem was increased to $14 \%$ by coadministration of three $100 \mathrm{mg} / \mathrm{kg}$ subcutaneous doses of RDHP inhibitor. In contrast, coadministration of the inhibitor had no effect on the urinary recovery of CP-65,207, a finding in agreement with the greater relative stability of CP-65,207 to RDHP in vitro (Table 3). Distinct differences between CP-65,207 and imipenem with respect to the effect of probenecid coadministration are also seen in Table 4. While coadministration of probenecid without RDHP inhibitor more than doubled the $\mathrm{AUC}$ and $\mathrm{T}_{1 / 2} \beta$ for CP-65,207, only a modest increase in these parameters for imipenem was observed with probenecid under similar conditions.
Fig. 8. Relationship between dose $(\mathrm{mg} / \mathrm{kg})$ and $\mathrm{AUC}_{0-\infty}(\mu \mathrm{g} \cdot$ hours $/ \mathrm{ml})$ in mice given oral doses of CP-65,207 POM ester.



Oral Absorption of CP-65,207 Prodrug Esters

The in vitro activity and in vivo performance of CP-65,207 encouraged the development of a POM ester formulation for testing as an oral delivery agent for parent drug. As shown in Fig. 8, good proportionality was observed in rats between AUC and oral doses of CP-65,207 POM ester from 10 to $40 \mathrm{mg} / \mathrm{kg}$. The percent of parent drug absorbed from the CP-65,207 POM ester in these studies, was determined from intravenous crossover tests to be from 52 to $68 \%$.

Further studies in the rat revealed that there were significant differences in the degree of absorption between the POM esters of the separate $S$ and $R$-isomers of CP-65,207. At doses of $50 \mathrm{mg} / \mathrm{kg}$, the oral bioavailability of the $S$-isomer POM ester was $76 \%$ compared to $36 \%$ for the ester of the corresponding $R$-isomer (Table 5). This differential in absorption of the isomers when tested individually, was not observed 
Table 5. Oral bioavailability in rats of POM esters of separate $S$ and $R$-isomers of CP-65,207.

\begin{tabular}{lcccc}
\hline & $\begin{array}{c}S \text {-Isomer }^{\mathrm{a}} \\
\text { (iv) }\end{array}$ & $\begin{array}{c}S \text {-Isomer } \\
\text { POM ester }^{\mathrm{b}}(\mathrm{po})\end{array}$ & $\begin{array}{c}R \text {-Isomer } \\
\text { (iv) }\end{array}$ & $\begin{array}{c}R \text {-Isomer } \\
\text { POM }^{\mathrm{a}} \text { ester }^{\mathrm{b}}(\mathrm{po})\end{array}$ \\
\hline $\mathrm{Cmax}(\mu \mathrm{g} / \mathrm{ml})$ & $28.4(3.1)^{\mathrm{c}}$ & $2.7(0.46)$ & $30.0(5.0)$ & $0.7(0.06)$ \\
$\mathrm{AUC}_{0-\infty}(\mu \mathrm{g} \cdot$ hours $/ \mathrm{ml})$ & $7.1(0.55)$ & $5.4(0.76)$ & $7.0(1.3)$ & $2.5(0.72)$ \\
Oral bioavailability $(\%)$ & - & $76^{\mathrm{d}}$ & - & 36 \\
\hline
\end{tabular}

a Intravenous crossover leg separate isomer dosed $50 \mathrm{mg} / \mathrm{kg}$.

b Oral dose leg with POM ester of separate isomer dosed $50 \mathrm{mg} / \mathrm{kg}$.

c Number in parenthesis designate $+1-1 \operatorname{SEM}(n=5)$.

d Percent oral bioavailability generated by dividing AUC po dose by AUC iv dose.

in absorption studies with the POM ester of CP-65,207 diastereomeric mixture. In the latter case, HPLC analysis of serum indicated that both isomers in the mixture were absorbed to approximately the same extent (data not shown).

\section{Absorption of CP-65,207 POM Ester in Monkeys}

In order to determine the efficiency of prodrug hydrolysis during the process of absorption in the intestine, studies were performed in the cynomolgus monkey to look for the presence of intact prodrug in the portal circulation. Following surgical access to the intestine, CP-65,207 prodrug was injected directly into the duodenum in an amount calculated to deliver $50 \mathrm{mg} / \mathrm{kg} \mathrm{CP}-65,207$. Blood samples were taken from the portal vein and femoral triangle and immediately processed for the presence of intact prodrug by HPLC. Additionally, serum was prepared from blood samples collected from the femoral triangle and assayed for both isomers of CP-65,207. Forty minutes after introduction of prodrug into the duodenum, the portal blood concentrations of intact prodrug were less than $0.4 \mu \mathrm{g} / \mathrm{ml}$ and no prodrug was detected in femoral blood. In contrast, peak portal blood concentrations of $3.8 \mu \mathrm{g} / \mathrm{ml}$ for CP-81,054 and $1.8 \mu \mathrm{g} / \mathrm{ml}$ for CP-70,429 were observed at 40 minutes. This suggests that the prodrug was efficiently hydrolyzed during absorption to deliver both isomers of CP-65,207 to portal blood, liver, and the peripheral circulation. The POM ester of CP-65,207 was also found to be stable in dog gastric fluid (pH 2.0), with essentially no hydrolysis to free penem occurring over a 90 -minute period as determined by the HPLC method.

\section{Comparative Efficacy of CP-70,429 and CP-81,054 Stereoisomers}

Pharmacokinetic studies showed differences in absorption of the esters of the separate isomers of CP-65,207 and in in vitro stability to human RDHP. However, previous studies showed no significant differences between the isomers in antimicrobial activity ${ }^{24}$. The data in Table 6 also indicate that there was no significant difference in the efficacy observed following subcutaneous administration of the separate isomers in protecting mice from lethal bacterial infections.

\section{Discussion}

In recent years there has been great interest in the discovery of new penem and carbapenem 
antimicrobials for clinical use. The interest in these $\beta$-lactams stems from their high stability to most $\beta$-lactamases, which confers a broad antibacterial spectrum and high potency on these compounds. In addition, some penems like SCH-29482 and the ester of FCE-22101 have shown oral absorption in humans, providing potential as potent oral antibiotics. Despite the large number of penem and carbapenem analogs that have been evaluated in vitro, only a small number have progressed to therapeutic trials. One of the reasons for this undoubtedly involves the unusual susceptibility of these agents to $R D H P^{13,17)}$ which causes extensive degradation of some compounds in the kidney with subsequent low urinary recovery. The inhibitor cilastatin (MK 0791) was developed for coadministration with imipenem in order to compensate for the hydrolytic activity of the renal enzyme in man ${ }^{12)}$.

CP-65,207 is a new penem antibiotic demonstrating antibacterial potency equivalent to imipenem against most clinical bacterial isolates with the exception of $P_{\text {seudomonas aeruginosa }}{ }^{18}$. The advantages of CP-65,207 over imipenem are its greater relative stability to RDHP and the existence of a prodrug ester suitable for an oral dose formulation. CP-65,207 is an equal mixture by weight of two diastereomers. HPLC analysis of serum obtained from cynomolgus monkeys dosed intravenously with the separate isomers of CP-65,207, indicated that both the $S$ and $R$-isomers were equally distributed in the bloodstream. Unlike penem SCH-29482, CP-65,207 was not highly bound to human serum. Initial results with CP-65,207 dosed parenterally in rodents, demonstrated relatively short elimination half-lives (13 and 18 minutes in mice and rats, respectively) similar to those observed with other penems and carbapenems ${ }^{9,15,16)}$. SCH-34343 for example, is reported to have a $\mathrm{T}_{1 / 2} \beta$ of 5.6 and 6.3 minutes respectively in mice and rats ${ }^{15}$. Dehydropeptidases have been found in extrarenal tissues in the rat, and the presence of these enzymes in organs such as the lung, have been shown to be the major sites of metabolism for these compounds ${ }^{17}$. Given the extensive metabolism of penems reported in rats, it is interesting that in the plot of $\mathrm{T}_{1 / 2} \beta$ vs. body weight ${ }^{25)}$ shown in Fig. 6, the values of CP-65,207 in mice, rats, dogs, cynomolgus monkeys, and man aligned in a linear fashion. It is possible that the relative stability of CP-65,207 to dehydropeptidase stabilizes its inactivation in rodent species, making its disposition proportional by weight when compared with the other species tested. In this regard, CP-65,207 resembles other new penems and carbapenems that demonstrate higher stability to $\operatorname{RDHP}^{26,27)}$.

It was of interest to note that the $S$-isomer $(C P-70,429)$ was more stable than the $R$-isomer to both porcine and human RDHP. CP-70,429 was 7.5-fold more stable than imipenem against the porcine enzyme and almost 2-fold more stable than the carbapenem against purified human RDHP. A number of in vivo studies have been performed with CP-65,207 in order to determine the significance of this greater relative stability to the renal enzymes. First, studies in the beagle dog indicate that renal elimination of CP-65,207 diastereomeric mixture is significantly less affected by RDHP than imipenem. This is seen by the greater urinary recovery of CP-65,207 in the dog (41 vs. $1 \%$ for imipenem) in the absence of RDHP inhibitor. The recovery in the urine of bioactive CP-65,207 was not increased by coadministration of a RDHP inhibitor. Published studies have indicated that in humans, one-third of the amount of imipenem undergoing clearance by the kidney is eliminated by active tubular secretion ${ }^{12)}$. This event is not measureable in the absence of RDHP inhibitor due to the rapid degradation of imipenem in the proximal tubule, thus coadministration of probenecid has no influence on the elimination of this compound unless a RDHP inhibitor is present as well ${ }^{12)}$. This relationship was confirmed in our studies in the beagle. In contrast to imipenem, the elimination of CP-65,207 was significantly influenced by probenecid alone, in the absence of RDHP inhibitor. This suggests that a significant proportion of the penem in the beagle is eliminated in the kidney by tubular secretion and this process is relatively insensitive to the activity of RDHP.

Studies with CP-65,207 in man have indicated that approximately 2-fold more intact CP-70,429 $S$-isomer is recovered in urine compared with the $R$-isomer CP-81,054 (46 vs. $26 \%$, respectively) following intravenous administration ${ }^{23}$. Thus the relative stability of the $S$-isomer of CP-70,429 to RDHP leads to consistently higher recovery of intact drug in human urine compared to the $R$-isomer.

Another characteristic of CP-65,207 is the existence of an oral dosage formulation. The first penem to have this characteristic was $\mathrm{SCH}-29482^{28)}$. This compound was highly serum protein bound (approximately $95 \%$ ), and demonstrated a relatively long elimination $T_{1 / 2}$ with high peak blood levels observed in all species tested compared to other penems ${ }^{28)}$. The development of this compound, however, was halted due to unacceptable side effects following metabolism in man. Other more recently developed oral penems include the ester of FCE-22101 (FCE-22891), where available data indicates that it has an 
oral absorption in rodents of $47 \%$ and a mean absorption in man of $29 \%$ following 40 and $14 \mathrm{mg} / \mathrm{kg}$ oral doses, respectively ${ }^{16,29)}$. At similar doses, the ester of CP-65,207 diastereomeric mixture gives slightly better absorption in both species. Further results in the rat with the oral ester of CP-70,429 ( $S$-isomer) suggest that this single isomer may provide a better oral formulation in man. Thus CP-70,429 in vivo has important advantages of being less susceptible to RDHP compared with imipenem and has the potential of being orally absorbed as the POM ester. These results suggest that further clinical studies with this penem isomer are warranted.

\section{References}

1) GootZ, T. D.; D. GrRard, G. Foulds \& W. U. SChelkly: Pharmacokinetics in animals of a new penem antibiotic CP-65,207. Program and Abstracts of the 28th Intersci. Conf. on Antimicrob. Agents Chemother., No. 222, p. 148, Los Angeles, Oct. 23 26, 1988

2) FAss, R. J.: In vitro activity of Sch 29482 against bacterial blood isolates. J. Antimicrob. Chemother. 9 (Suppl. C): S153 S157, 1982

3) Matsuda, K.; K. SaSAKI, K. Inoue, H. Kondo, M. Inoue \& S. Mitsuhashi: In vitro antibacterial activity of Sch 34343 and its stability to $\beta$-lactamases and renal dehydropeptidase 1. Antimicrob. Agents Chemother. 28: $684 \sim 688,1985$

4) Neu, H. C.; N. X. Chin \& P. LABThavikuL: The in-vitro activity of a novel penem FCE 22101 compared to other $\beta$-lactam antibiotics. J. Antimicrob. Chemother. 16: 305 313, 1985

5) NORRBY, S. R. \& M. JONSSON: Comparative in vitro antibacterial activity of Sch 34343, a novel penem antibiotic. Antimicrob. Agents Chemother. 27: 128 131, 1985

6) Ohya, S.; Y. Utsui, S. Sugawara \& M. Yamazaki: Penem derivatives: $\beta$-Lactamase stability and affinity for penicillin-binding proteins in Escherichia coli. Antimicrob. Agents Chemother. 21: 492 497, 1982

7) Van der Auwera, P.; F. Ernst, P. Grenier, Y. Glupczynski, M. Husson \& J. Klastersky: In vitro activity of two new carbapenems FCE 22101 and CGP 31608 in comparison with imipenem. J. Antimicrob. Chemother. 20: $179 \sim 189,1987$

8) WiSE, R.; J. ANDREWS \& L. PidDock: In vitro activity of CGP-31608, a new penem. Antimicrob. Agents Chemother. 31: $267 \sim 273,1987$

9) Zak, O.; M. Lang, R. Cozens, E. Konopka, H. Mett, P. Schneider, W. Tosch \& R. Scartazzini: Penems: in vitro and in vivo experiments. J. Clin. Pharmacol. 28: 128 135, 1988

10) HARPER, C.; A. ReNÉ \& B. J. CAMPBell: Renal dipeptidase: localization and inhibition. Biochim. Biophys. Acta 242: 446 458, 1971

11) Kropp, H.; J. G. SUndelof, R. Hajdu \& F. M. Kahan: Metabolism of thienamycin and related carbapenem antibiotics by the renal dipeptidase, dehydropeptidase-I. Antimicrob. Agents Chemother. 22: 62 70, 1982

12) Kahan, F. M.; H. Kropp, J. G. Sundelof \& J. Birnbaum: Thienamycin: development of imipenem-cilastatin. J. Antimicrob. Chemother. 12 (Suppl. D): S1 $\sim$ S35, 1983

13) Norrby, S. R.; K. Alestig, B. Björnegård, L. Å. Burman, F. Ferber, J. Huber, K. H. Jones, F. M. Kahan, J. S. KaHAN, H. Kropp, M. A. P. Meisinger \& J. G. SUndelof: Urinary recovery of $N$-formimidoyl thienamycin (MK0787) as affected by coadministration of $N$-formimidoyl thienamycin dehydropeptidase inhibitors. Antimicrob. Agents Chemother. 23: 300 307, 1983

14) Wang, C.; G. B. Calandra, M. Aziz \& K. Brown: Efficacy and safety of imipenem/cilastatin: A review of worldwide clinical experience. Rev. Infect. Dis. 7 (Suppl. 3): S528 S536, 1985

15) Chung, M.; E. Radwanski, D. Loebenberg, C.-C. Lin, E. Oden, S. Symchowicz, R. P. Gural \& G. H. Miller: Interspecies pharmacokinetic scaling of Sch 34343. J. Antimicrob. Chemother. 15 (Suppl. C): S227 S233, 1985

16) Franceschi, G.; M. Foglio, M. Alpegiani, C. Battistini, A. Bedeschi, E. Perrone, F. Zarini, F. Arcamone, C. D. Bruna \& A. SANFILIPpo: Synthesis and biological properties of sodium $(5 R, 6 S, 8 R)$-6 6 -hydroxyethyl-2carbamoyloxymethyl-2-penem-3-carboxylate (FCE 22101) and its orally absorbed esters FCE 22553 and FCE 22891. J. Antibiotics 36: $938 \sim 941,1983$

17) Hajdu, R.; K. Hayase, J. Sundelof, K. Hara, H. Kropp \& F. Kahan: Cilastatin-sensitive lactamase active on carbapenem and penem antibiotics in the lung of rodents. In Recent Advances in Chemotherapy. Antimicrobial Section 2. Ed., J. Ishigami, pp. $1211 \sim 1214$, University of Tokyo Press, 1985

18) Gootz, T.; J. Retsema, A. Girard, E. Hamanaka, M. Anderson \& S. Sokolowski: In vitro activity of CP-65,207, a new penem antimicrobial agent, in comparison with those of other agents. Antimicrob. Agents Chemother. 33: $1160 \sim 1166,1989$

19) English, A. R.; D. Girard \& S. HAskell: Pharmacokinetics of sultamicillin in mice, rats, and dogs. Antimicrob. Agents Chemother. 25: 599 602, 1984 
20) English, A. R.; D. Girard \& J. A. Retsema: Pirbenicillin: Pharmacokinetic parameters in mice. Antimicrob. Agents Chemother. 10: 491 497, 1976

21) Welch, C. L. \& B. J. CAMPBell: Uptake of glycine from 1-alanylglycine into renal brush border vesicles. J. Membrane Biol. 54: $39 \sim 50,1980$

22) Gootz, T. D.; T. A. SUbashi \& D. G. Lindner: Simple spectrophotometric assay for measuring protein binding of penem antibiotics to human serum. Antimicrob. Agents Chemother. 32: 159 163, 1988

23) Foulds, G.; A. K. Knirsch, T. G. Tensfeldt, N. Gerber \& J. HoucK: The kinetics of penem CP-65,207 in man. Program and Abstracts of the 28th Intersci. Conf. on Antimicrob. Agents Chemother., No. 223, p. 148, Los Angeles, Oct. $23 \sim 26,1988$

24) Campbell, B.; A. English, G. Foulds, A. Girard, T. Gootz, J. Jasys, P. Kelbaugh, M. Kellogg, E. Hamanaka, D. Lindner, D. NASON, J. Retsema \& R. VolkmanN: CP-65,207-(5R,6S)-6-[(R)-1-hydroxyethyl]-2-[(RS)-1oxotetrahydrothiophene-( $S R)$-3-yl-thio]-penems. Program and Abstracts of the 28th Intersci. Conf. on Antimicrob. Agents Chemother., No. 220, p. 148, Los Angeles, Oct. $23 \sim 26,1988$

25) MoRDENTI, J.: Forecasting cephalosporin and monobactam antibiotic half-lives in humans from data collected in laboratory animals. Antimicrob. Agents Chemother. 27: 887 891, 1985

26) Guthikonda, R; L. Cama, M. Quesada, M. Woods, T. Salzmann \& B. Christensen: Structure-activity relationships in the 2-arylcarbapenem series: synthesis of 1-methyl-1-2-arylcarbapenems. J. Med. Chem. 30: $871 \sim 880,1987$

27) Kim, C. U.; P. F. Misco, B. Y. LuH \& M. J. M. HrtchCock: Synthesis and in vitro activity of C-2 quaternary heterocyclic alkylthio carbapenems. J. Antibiotics 40: 1707 1715, 1987

28) Loebengerg, D.; G. H. Miller, E. L. Moss, Jr., E. Oden, R. S. Hare, M. Chung \& J. A. Waitz: Evaluation of the in-vivo activity of Sch 29482. J. Antimicrob. Chemother. 9 (Suppl. C): S221 S231, 1982

29) Webberley, J. M.; R. Wise, J. M. Andrews, J. P. Ashby \& D. Wallbridge: The pharmacokinetics and tissue penetration of FCE 22101 following intravenous and oral administration. J. Antimicrob. Chemother. $21: 445 \sim 450$, 1988 